Pacific Journal of Mathematics

ON THE OSCULATORY AND ASYMPTOTIC BEHAVIOR OF
SOLUTIONS OF FIFTH ORDER SELFADJOINT DIFFERENTIAL
ELUTIONS

WILLIE TAYLO 


\title{
ON THE OSCILLATORY AND ASYMPTOTIC BEHAVIOR OF SOLUTIONS OF FIFTH ORDER SELFADJOINT DIFFERENTIAL EQUATIONS
}

\author{
W. E. TAYLOR, JR.
}

\begin{abstract}
In this paper the fifth order selfadjoint differential equation
\end{abstract}

$$
\left(z^{\prime \prime \prime}+2 p(x) z\right)^{\prime}+2 p(x) z^{\prime}=0
$$

is considered under the assumption that $p(x)$ is a positive continuous function defined on the half axis $[0, \infty)$. The oscillation and asymptotic properties of certain solutions of (1) will be discussed after which connections between the solutions of (1) and the solutions of the fourth order differential equation

$$
y^{\prime \prime \prime \prime}-p(x) y=0
$$

are investigated. More spcifically, it is shown that (1) is oscillatory if and only if (2) is oscillatory.

While the literature is unusually scanty on the solutions of odd order selfadjoint differential equations, oscillation properties of the selfadjoint third order equation

$$
\left(y^{\prime \prime}+2 b(x) y\right)^{\prime}+2 b(x) y^{\prime}=0
$$

has been studied by several authors, including J. H. Barrett [3], G. D, Jones [4] and S. C. Tefteller [7]. All of these works utilized the fact that if $u$ and $v$ are solutions of

$$
w^{\prime \prime}+b(x) w=0
$$

then the functions $u^{2}, u v$, and $v^{2}$ are solutions of (3).

Recall that a nontrivial solution of (1) or (2) is said to be oscillatory if it has arbitrarily large zeros, otherwise it is termed nonoscillatory. In case (1) has an oscillatory solution we say that (1) is oscillatory. A similar definition holds for equation (2). For convenience, the term "solution" for the remainder of this work will refer to nontrivial solutions unless otherwise noted.

Tefteller in [7] proved that (3) is oscillatory if and only if (4) is oscillatory. While in [4] it was shown that if (3) is oscillatory then the solution space of (3) has a basis with $i$ oscillatory solutions and $3-i$ nonoscillatory solutions for $i=0,1,2,3$. It is these observations and the aforementioned connections between the solutions of (1) and (2) that motivates this study. Finally, we refer to the 
works of Ahmad [1] and Leighton and Nehari [5] on selfadjoint fourth order differential equations.

II. Zero properties of solutions. In order to facilitate our study of (1), the following definitions are needed:

Definition. A solution $z$ of $(1)$ is said to have an $(i, j)$-distribution of zeros if it has a zero of multiplicity $i$ followed by a zero of multiplicity $j$. For $t \geqq 0, r_{i j}(t)$ is the infimum of the set of numbers $b>t$ such that there is a nontrivial solution of (1) having an $(i, j)$-distribution of zeros on $[t, b]$. Equation (1) is termed $(i, j)$ disconjugate if no solution has an $(i, j)$-distribution of zeros.

Definition. The first conjugate point of $t, \eta_{1}(t)$, is the smallest number $s>t$ such that there exists a nontrivial solution of (1) which vanishes at $t$ and has five zeros on $[t, s]$.

In his paper [6], T. L. Sherman has established for $n$th order linear differential equations that

$$
\eta_{1}(t)=\min _{i+j=n}\left\{r_{i j}(t)\right\}
$$

Applying this result to (1) and using the selfadjointness of (1) it is clear that

$$
\eta_{1}(t)=\min \left\{r_{32}(t), r_{41}(t)\right\}
$$

Lemma 2.1. If $z$ is a solution of (1), then

$$
J(z)=z\left(z^{\prime \prime \prime}+2 p(x) z\right)-z^{\prime} z^{\prime \prime \prime}+1 / 2 z^{\prime \prime 2}
$$

is a constant determined by the initial values of $z$. Furthermore, for a solution $z$ of (1), the functional

$$
F(z)=z z^{\prime \prime \prime}-2 z^{\prime} z^{\prime \prime}
$$

is nonincreasing on $[0, \infty)$ whenever $J(z) \leqq 0$.

Proof. Computing $J^{\prime}(z)$ and making appropriate substitutions from (1), we find that $J^{\prime}(z) \equiv 0$, from which the first part of the lemma follows. For the proof of the remaining part of the lemma, note that $F^{\prime}(z)=J(z)-5 / 2 z^{\prime 2}-2 p(x) z^{2}$.

THEOREM 2.2. Equation (1) is both (2,3)-disconjugate and (3, 2)disconjugate on $(0, \infty)$. 
Proof. Suppose $z$ is a solution of (1) having a zero of multiplicity at least three at $x=a, a>0$. Then $J(z) \equiv 0$ and consequently, $F[z]$ is decreasing. Thus $0<x<a$ implies $F[z(x)]>0$ and $a<x$ implies $F[z(x)]<0$, from which it follows easily that $z$ cannot have a multiple zero to the right nor left of $x=a$.

CoRollary 2.3. Let $u$ and $v$ be independent solutions of (1) having triple zeros at $x=c$. Then $W(u, v)(x)=u(x) v^{\prime}(x)-v(x) u^{\prime}(x) \neq 0$ for $x \neq c$. Consequently, the zeros of $u$ and $v$ separate each other on $[0, c)$ and $(c, \infty)$.

From (5) and Theorem 2.2 we can now obtain more precise information about how the first conjugate points are determined, namely

\section{THEOREM 2.4. If $\eta_{1}(t)$ exists for $t \geqq 0$, then $\eta_{1}(t)=r_{41}(t)$.}

III. Oscillation properties. Using $J(z)$ and $F(z)$ defined above we now group the solutions of (1) into three distinct classes. A solution $z$ of (1) is termed Type $A$ if $J(z) \equiv 0$ and $F[z]>0$ on $[0, \infty)$, Type $B$ if $J(z) \leqq 0$ and $F[z] \leqq 0$ on $[b, \infty)$, for some $b>0$. Finally, a Type $C$ solution is any solution $z$ with $J(z)>0$.

To obtain results concerning the solutions in these various classes we will need the so-called "double zero" lemma.

Lemma 3.1. Suppose $u, v \in C^{\prime}[a, b]$ and satisfies $u(\alpha)=u(\beta)=0$, $a<\alpha<\beta<b, u(x) \neq 0$ on $(\alpha, \beta)$ and $v(x) \neq 0$ on $[\alpha, \beta]$. Then some nontrivial linear combination of $u$ and $v$ has a double zero in $(\alpha, \beta)$.

The condition $r_{41}(t)<\infty$ for each $t \geqq 0$ is both necessary and sufficient for the oscillation of (1) as we see in our next result.

THEOREM 3.2. Equation (1) is oscillatory if and only if $r_{41}(t)<\infty$ for each $t$.

Proof. Suppose (1) is oscillatory and that $r_{41}(t)=\infty$ for some $t$. Then $r_{41}(s)=\infty$ for all $s>t$ and so (1) is disconjugate on $(t, \infty)$, contradicting the fact that (1) has an oscillatory solution.

For the converse suppose $r_{41}(t)<\infty$ for all $t$. We will show that Type $B$ solutions are oscillatory.

Suppose there is a nonoscillatory Type $B$ solution. Then there is a number $b$ and a solution $y(x)$ of (1) satisfying $y(x)>0$ on $[b, \infty)$, $F[y(x)]<0$ on $[b, \infty)$ and $J(y) \leqq 0$. Let $u(x)$ be a solution of (1) having a $(4,1)$-distribution of zeros, say at $x=c$ and $x=d$, where $b \leqq$ 
$c \leqq d$ and $u(x) \neq 0$ on $(c, d)$. We assume without loss of generality that $u^{\prime \prime \prime \prime}(c)=1$. Since $y(x)>0$ on $(c, d)$ and $u(x)>0$ on $(c, d)$, there is a positive constant $k$ such that $v(x)=y(x)-k u(x)$ has a double zero in $(c, d)$. Since $F[v(x)]$ is decreasing $(J(v) \leqq 0)$ it follows that $F[v(c)]>0$. But $F[v(c)]=F[y(c)]<0$, a contradiction. Consequently, it follows that $y(x)$ must be oscillatory. Using the fact that $r_{41}(t)=$ $r_{14}(t)$ and making some easy modifications in the above argument we can show that Type $A$ solutions must oscillate.

CoRollary. If (1) is oscillatory then every Type $A$ and Type $B$ solution is oscillatory.

CoROllary. If (1) is oscillatory then a nonoscillatory solution is Type $C$.

While it is clear that Type $B$ and Type $C$ solutions exist, our next result shows that equation (1) always has a Type $A$ solution.

THEOREm 3.4. There exists a Type $A$ solution of equation (1).

Proof. Suppose $a \geqq 0$. Let $\left\{x_{n}\right\}_{n=1}^{\infty}$ be an increasing sequence of points such that $a<x_{1}$ and $\lim _{n \rightarrow \infty} x_{n}=\infty$. (1).

Let $z_{1}(x), z_{2}(x), z_{3}(x), z_{4}(x), z_{5}(x)$ be five independent solutions of

Define

$$
u_{n}(x)=c_{1 n} z_{1}(x)+c_{2 n} z_{2}(x)+c_{3 n} z_{3}(x)+c_{4 n} z_{4}(x)+c_{5 n} z_{5}(x)
$$

where

$$
\begin{gathered}
u_{n}(a)=0, \\
u_{n}\left(x_{n}\right)=u_{n}^{\prime}\left(x_{n}\right)=u_{n}^{\prime \prime}\left(x_{n}\right)=0
\end{gathered}
$$

and

$$
c_{1 n}^{2}+c_{2 n}^{2}+c_{3 n}^{2}+c_{4 n}^{2}+c_{5 n}^{2}=1
$$

Note that $J\left(u_{n}(x)\right) \equiv 0$ and $F\left[u_{n}(x)\right]>0$ on $\left[0, x_{n}\right)$, for each $n$.

The sequences $\left\{c_{i n}\right\}_{n=1}^{\infty}$ for $i=1,2,3,4,5$ are bounded and hence we can assume without loss of generality that $\lim _{n \rightarrow \infty} c_{i n}=c_{i}, n=$ $1,2,3,4,5$. Since $c_{1}^{2}+c_{2}^{2}+c_{3}^{2}+c_{4}^{2}+c_{5}^{2}=1$, it follows that

$$
u(x)=c_{1} z_{1}(x)+c_{2} z_{2}(x)+c_{3} z_{3}(x)+c_{4} z_{4}(x)+c_{5} z_{5}(x)
$$

is a nontrivial solution of (1).

We claim that $u(x)$ is Type $A$. First note that $F\left[u_{n}(x)\right]>0$ on $\left[0, x_{n}\right)$, consequently, $F[u(x)] \geqq 0$ on $[0, \infty)$. 
If $F\left[u\left(x_{0}\right)\right]=0$ for some $x_{0} \geqq 0$, then $F[u(x)] \equiv 0$ on $\left[x_{0}, \infty\right)$, but this implies $\left.\left.F^{\prime}[u(x)]=-5 / 2 u^{\prime \prime 2}(x)-2 p(x) u^{2}\right) x\right) \equiv 0$, contradicting the fact that $u(x)$ is nontrivial. Therefore we must have $F[u(x)]>0$ on $[0, \infty)$.

In the previous proof note that the Type $A$ solution $u$ constructed vanished at $x=a$. If $x=b$ is a point such that $u(b) \neq 0$, then a Type $A$ solution which vanishes at $x=b$ can be constructed which is clearly independent of the one which vanished at $x=a$. Thus equation (1) has at least two independent Type $A$ solutions.

We now list some properties of Type $A$ solutions.

THeOREM 3.5. Suppose (1) has an oscillatory solution. Let $z$ be a Type A solution of (1), then the following hold:

(i) $\int_{\text {(ii) }}^{\infty} \int^{\prime \prime 2} p(x) d x<\infty, z^{2}(x) d x<\infty$, and
(iii) $z^{\prime}$ is bounded.

Proof. Since $J(z) \equiv 0, F[z(x)]$ is decreasing. By differentiating $F[z(x)]$ and then integrating from 0 to $x$, we obtain

$$
0<F[z(x)]=F[z(0)]-\frac{5}{2} \int_{0}^{x} z^{\prime \prime 2}(t) d t-\frac{3}{2} \int_{0}^{x} p(t) z^{2}(t) d t
$$

from which (i) and (ii) follow.

To prove (iii) note that

$$
0<F[z(x)]=z(x) z^{\prime \prime \prime}(x)-2 z^{\prime}(x) z^{\prime \prime}(x)=\left[z(x) z^{\prime \prime}(x)-\frac{3}{2} z^{\prime 2}(x)\right]^{\prime} \text {. }
$$

Clearly $F[z(x)] \rightarrow 0$ as $x \rightarrow \infty$, for if not, we would have $z(x) z^{\prime \prime}(x)-$ $3 / 2 z^{\prime 2}(x) \rightarrow \infty$ as $x \rightarrow \infty$ which is obviously impossible since $z(x)$ is oscillatory. Since $z(x) z^{\prime \prime}(x)-3 / 2 z^{\prime 2}(x)$ is negative and increasing, letting $x \rightarrow \infty$ along the zeros of $z^{\prime \prime}(x)$ we see that $z^{\prime}(x)$ is bounded. proof.

For Type $B$ solutions we offer the following result, but omit the

TheOREM 3.6. Suppose (1) has an oscillatory solution. Let $z$ be a Type $B$ solution with $J(z)<0$, then

(i ) Either $\int^{\infty} p(x) z^{2}(x) d x=\infty$ or $\int^{\infty} z^{\prime 2}(x) d x=\infty$, and

(iii) lim $\sup _{x \rightarrow \infty} z^{\prime}(x)=\infty$, i.e., $z^{\prime}(x)$ is unbounded.

For the case $p(x) \equiv 1$, the resulting equation for (1) is

$$
z^{\prime \prime \prime \prime}+4 z^{\prime}=0 \text {. }
$$


A basis for the solution space of (6) is

$$
\left\{e^{x} \sin x, e^{x} \cos x, e^{-x} \sin x, e^{-x} \cos x, 1\right\} .
$$

Note that the solutions $e^{-x} \sin x$ and $e^{x} \sin x$ are Type $A$ and Type $B$ solutions of (6), respectively, and satisfy the conclusions of Theorems 3.5 and 3.6 .

In the preceding example we note that (6) has a nonoscillatory solution. To show that this is true in general we proceed through equation (2).

THEOREM 3.7. Let $u$ and $v$ be independent solutions of

$$
y^{\prime \prime \prime}-p(x) y=0 \text {. }
$$

Then $z(x)=u(x) v^{\prime}(x)-v(x) u^{\prime}(x)$ is a solution of $(\mathbf{1})$.

It is well known [1] that (2) has a pair of solutions $u$ and $v$ satisfying

$$
u(x)>0, \quad u^{\prime}(x)>0, \quad u^{\prime \prime}(x)>0, \quad u^{\prime \prime \prime}(x)>0,
$$

and

$$
v(x)>0, \quad v^{\prime}(x)<0, \quad v^{\prime \prime}(x)>0, \quad v^{\prime \prime \prime}(x)<0
$$

on $[0, \infty)$. Clearly the Wronskian of this pair of solutions does not vanish on $[0, \infty)$ and we have proven

THEOREM 3.8. Equation (1) has a nonvanishing solution.

Actually (1) always has at least three independent nonoscillatory solutions. Whether or not three is the maximum possible when (1) is oscillatory remains an open question.

Finally, we establish a connection between the oscillation of (1) and the oscillation of (2).

THeOREM 3.9. Equation (1) is oscillatory if and only if (2) is oscillatory.

Proof. Suppose (2) is oscillatory. Let $u$ be an oscillatory solution of (2). Suppose $v$ is a nonoscillatory solution of (1) satisfying either (7) or (8). Then $z=u v^{\prime}-v u^{\prime}$ is an oscillatory solution of (1).

For the converse, suppose (2) is nonoscillatory, then (2) is eventually disconjugate, see [5]. So there exists $a \geqq 0$ so that no solution of (2) has more than three zeros on $[a, \infty)$. Let $y_{1}$ and $y_{2}$ be 
independent solutions of (2) having double zeros at $x=a$. Then $W\left(y_{1}, y_{2}\right)(x) \neq 0$ for $x>a$, for if $W\left(y_{1}, y_{2}\right)(\bar{x})=0$ for some $\bar{x}>a$, then some combination of $y_{1}$ and $y_{2}$ has four zeros on $[a, \bar{x}]$ contradicting the fact that (2) is disconjugate on $[a, \infty)$. But $z=W\left(y_{1}, y_{2}\right)$ is a solution of (1) having a zero of order four at $x=a$. Thus $\eta_{1}(a)=r_{41}(a)=\infty$ since $z$ does not vanish on $(a, \infty)$. Consequently, (1) is nonoscillatory, in fact, disconjugate on $(a, \infty)$.

\section{REFERENCES}

1. S. Ahmad, On the oscillation of solutions of a class of linear fourth order differential equations, Pacific J. Math., 34 (1970), 289-299.

2. P. Appel, Sur la transformation des equations differentielle lineares, Comptes Rendus des Seances, 91 (1880), 211-214.

3. J. H. Barrett, Canonical forms of third order linear differential equations, Annali di Math., 65 (1964), 253-274.

4. G. D. Jones, A property of $y^{\prime \prime \prime}+p(x) y^{\prime}+1 / 2 p^{\prime}(x) y=0$, Proc. Amer. Math. Soc., 33 (1972), 420-422.

5. W. Leighton and Z. Nehari, On the oscillation of solutions of selfadjoint linear differential equations of the fourth order, Trans. Amer. Math. Soc., 89 (1958), 325-377. 6. T. L. Sherman, Properties of solutions of $n$th order linear differential equations, Pacific J. Math., 15 (1965), 1045-1060.

7. S. C. Tefteller, Concerning solutions of third order self-adjoint differential equations, Annali di Matematica, 96 185-192.

Received October 3, 1977.

Prairie View A \& M University

Prairie View, TX 77445 



\title{
PACIFIC JOURNAL OF MATHEMATICS
}

\section{EDITORS}

RICHARD ARENS (Managing Editor)

University of California

Los Angeles, CA 90024

Charles W. Curtis

University of Oregon

Eugene, OR 97403

C. C. MOORE

University of California

Berkeley, CA 94720
J. DUGUNDJI

Department of Mathematics

University of Southern California

Los Angeles, CA 90007

R. Finn and J. Milgram

Stanford University

Stanford, CA 94305

\section{ASSOCIATE EDITORS}
E. F. BECKENBACH
B. H. Neumann
F. WOLF
K. YosHidA

\section{SUPPORTING INSTITUTIONS}

\author{
UNIVERSITY OF BRITISH COLUMBIA \\ CALIFORNIA INSTITUTE OF TECHNOLOGY \\ UNIVERSITY OF CALIFORNIA \\ MONTANA STATE UNIVERSITY \\ UNIVERSITY OF NEVADA, RENO \\ NEW MEXICO STATE UNIVERSITY \\ OREGON STATE UNIVERSITY \\ UNIVERSITY OF OREGON
}

\author{
UNIVERSITY OF SOUTHERN CALIFORNIA \\ STANFORD UNIVERSITY \\ UNIVERSITY OF HAWAII \\ UNIVERSITY OF TOKYO \\ UNIVERSITY OF UTAH \\ WASHINGTON STATE UNIVERSITY \\ UNIVERSITY OF WASHINGTON
}

The Supporting Institutions listed above contribute to the cost of publication of this Journal, but they are not owners or publishers and have no responsibility for its content or policies.

Mathematical papers intended for publication in the Pacific Journal of Mathematics should be in typed form or offset-reproduced, (not dittoed), double spaced with large margins. Please do not use built up fractions in the text of the manuscript. However, you may use them in the displayed equations. Underline Greek letters in red, German in green, and script in blue. The first paragraph or two must be capable of being used separately as a synopsis of the entire paper. Items of the bibliography should not be cited there unless absolutely necessary, in which case they must be identified by author and journal, rather than by item number. Manuscripts, in triplicate, may be sent to any one of the editors. Please classify according to the scheme of Math. Reviews, Index to Vol. 39. All other communications should be addressed to the managing editor, or Elaine Barth, University of California, Los Angeles, California, 90024.

50 reprints to each author are provided free for each article, only if page charges have been substantially paid. Additional copies may be obtained at cost in multiples of 50 .

The Pacific Journal of Mathematics is issued monthly as of January 1966. Regular subscription rate: $\$ 72.00$ a year (6 Vols., 12 issues). Special rate: $\$ 36.00$ a year to individual members of supporting institutions.

Subscriptions, orders for numbers issued in the last three calendar years, and changes of address should be sent to Pacific Journal of Mathematics, P.O. Box 969, Carmel Valley, CA 93924, U.S.A. Older back numbers obtainable from Kraus Periodicals Co., Route 100, Millwood, NY 10546.

PUBLISHED BY PACIFIC JOURNAL OF MATHEMATICS, A NON-PROFIT CORPORATION

Printed at Kokusai Bunken Insatsusha (International Academic Printing Co., Ltd.). 8-8, 3-chome, Takadanobaba, Shinjuku-ku, Tokyo 160, Japan.

Copyright (C) 1978 by Pacific Journal of Mathematics Manufactured and first issued in Japan 


\section{Pacific Journal of Mathematics}

Vol. 77, No. $2 \quad$ February, 1978

Graham Donald Allen, Duals of Lorentz spaces ................... 287

Gert Einar Torsten Almkvist, The number of nonfree components in the decomposition of symmetric powers in characteristic p .......... 293

John J. Buoni and Bhushan L. Wadhwa, On joint numerical ranges ...... 303

Joseph Eugene Collison, Central moments for arithmetic functions . . . . . . 307

Michael Walter Davis, Smooth G-manifolds as collections of fiber

bundles ........................................ 315

Michael E. Detlefsen, Symmetric sublattices of a Noether lattice......... 365

David Downing, Surjectivity results for $\phi$-accretive set-valued

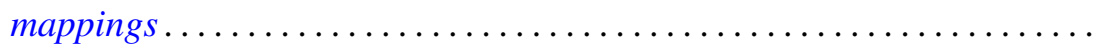

David Allyn Drake and Dieter Jungnickel, Klingenberg structures and partial designs. II. Regularity and uniformity ................. 389

Edward George Effros and Jonathan Rosenberg, $C^{*}$-algebras with approximately inner flip .......................... 417

Burton I. Fein, Minimal splitting fields for group representations. II. . . . . 445

Benjamin Rigler Halpern, A general coincidence theory ............. 451

Masamitsu Mori, A vanishing theorem for the mod $p$ Massey-Peterson spectral sequence ................................ 473

John C. Oxtoby and Vidhu S. Prasad, Homeomorphic measures in the

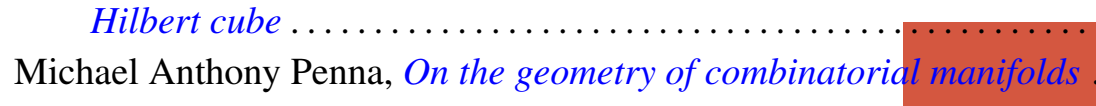

Robert Ralph Phelps, Gaussian null sets and differentiability of Lipschitz map on Banach spaces........................

Herbert Silverman, Evelyn Marie Silvia and D. N. Telage, Locally univalent functions and coefficient distortions...

Donald Curtis Taylor, The strong bidual of $\Gamma(K)$

Willie Taylor, On the oscillatory and asymptotic behavior of solutions of fifth order selfadjoint differential equations ...........

Fu-Chien Tzung, Sufficient conditions for the set of Hausdorff compactifications to be a lattice. 